(๑) Коллектив авторов, 2021

УДК 616-006.48:616-006.484:616-006.484.04:612.017:577.1

DOI - https://doi.org/10.14300/mnnc.2021.16106

ISSN - 2073-8137

РОАЬ ЦИТОКИНОВ В ФОРМИРОВАНИИ

ИММУНОАОГИЧЕСКОГО МИКРООКРУЖЕНИЯ

ПРИ НИЗКОАИФФЕРЕНЦИРОВАННЫХ ГАИОМАХ ГОАОВНОГО МОЗГА, ИХ ЗНАЧИМОСТЬ АЛЯ АИАГНОСТИКИ И ИММУНОТЕРАПИИ

О. И. Кит, С. Н. Игнатов, Е. Ю. Златник, Н. В. СолАаткина,

Э. Е. Росторгуев, А. Б. Сагакянц, О. Г. Шульгина

Национальный МеАицинский исслеАовательский центр онкологии, Ростов-на-Аону, Российская ФеАерация

\title{
ROLE OF CYTOKINES IN THE FORMATION OF IMMUNOLOGICAL MICROENVIRONMENT IN LOW-GRADE BRAIN GLIOMAS, THEIR SIGNIFICANCE FOR DIAGNOSIS AND IMMUNOTHERAPY
}

Kit O. I., Ignatov S. N., Zlatnik E. Yu., Soldatkina N. V., Rostorguev E. E., Sagakyants A. B., Shulgina O. G.

National Medical Research Centre for Oncology, Rostov-on-Don, Russian Federation

Глиальные опухоли составляют 35,5 \% от общего числа опухолей ЦНС, а глиобластома (ГБ) - 54 \% в структуре глиальных опухолей. Медиана выживаемости при ГБ составляет около 15 месяцев. Наряду с гистологическими особенностями опухолей не менее важными прогностическими критериями являются молекулярно-генетические аберрации. Так, на основании наличия мутации в гене IDH сформулирована концепция «вторичной глиобластомы», формирование которой невозможно без преобладания иммуносупрессивного микроокружения, в том числе изменения цитокинового состава. Приводится обзор литературы на основе анализа базы данных Pubmed о функциях, прогностической роли ряда цитокинов и возможного их использования в качестве мишеней для терапии ГБ.

Ключевые слова: глиобластома, низкодифференцированные глиальные опухоли, цитокиновое микроокружение глиальных опухолей

Glial tumors account for $35.5 \%$ of all CNS tumors, and $54 \%$ of glial tumors are glioblastomas (GB). The median survival in GB is about 15 months. Important prognostic criteria, along with histological characteristics of the tumor, include molecular genetic aberrations. Based on the presence of IDH gene mutation, was formulated the concept of «secondary glioblastoma», and proved that its formation is impossible without immunosuppressive microenvironment, including changes in the cytokine composition. This article provides a literature review based on an analysis of the Pubmed database about functions and the prognostic role of some cytokines and their possible use as targets for GB therapy.

Keywords: glioblastoma, low-grade glial tumors, cytokine microenvironment of glial tumors

Для цитирования: Кит О. И., Игнатов С. Н., Златник Е. Ю., Солдаткина Н. В., Росторгуев Э. Е., Сагакянц А. Б. ШУЛЬГИНа О. Г. РОЛЬ ЦИТОКИНОВ В ФОРМИРОВАНИИ ИММУНОЛОГИЧЕСКОГО МИКРООКРУЖЕНИЯ ПРИ НИЗКОДИФФЕРЕНЦИРОВАННЫХ ГЛИОМАХ ГОЛОВНОГО МОЗГА, ИХ ЗНАЧИМОСТЬ ДЛЯ ДИАГНОСТИКИ И ИММУНОТЕРАПИИ. Медицинский вестник Северного Кавказа. 2021;16(4):433-438. DOI - https://doi.org/10.14300/mnnc.2021.16106

For citation: Kit O. I., Ignatov S. N., Zlatnik E. Yu., Soldatkina N. V., Rostorguev E. E., Sagakyants A. B., Shulgina O. G. ROLE OF CYTOKINES IN THE FORMATION OF IMMUNOLOGICAL MICROENVIRONMENT IN LOW-GRADE BRAIN GLIOMAS, THEIR SIGNIFICANCE FOR DIAGNOSIS AND IMMUNOTHERAPY. Medical News of North Caucasus. 2021;16(4):433-438. DOI - https://doi.org/10.14300/mnnc.2021.16106 (In Russ.)

ГБ - глиобластома

КСФ - колониестимулирующий фактор

ТЭЛА - тромбоэмболия легочной артерии

ФНО - фактор некроза опухоли

ФР - фактор роста

HGG - низкодифференцированная глиальная опухоль
IFN - интерферон

IL - интерлейкин

LAK - лимфокин-активированные киллеры

LGG - высокодифференцированная глиальная опухоль

NK-клетки - натуральные киллеры 
огласно данным CBTRUS частота выявляемости первичных злокачественных опухолей головного мозга в США в 2018 году составила 121277 случаев, а в пересчете на 100000 населения - 7,12 случая. В среднем в США регистрируется до 16000 летальных исходов в год от первичных злокачественных опухолей головного мозга. В России частота встречаемости первичных злокачественных новообразований головного мозга в 2017 году составила 6,02 на 100000 населения [1].

Глиальные опухоли составляют 35,5 \% от общего числа опухолей ЦНС, а глиобластома (ГБ) - $54 \%$ в структуре глиальных опухолей [2, 3]. Медиана выживаемости при ГБ составляет около 15 месяцев [4].

Причины формирования глиальных опухолей до сих пор не ясны. По мнению ряда авторов, они связаны с нарушением пролиферации нейроэпителиальных клеток на фоне аберраций генотипа с последующей дисфункцией микроглии, изменением цитокинового состава $[3,5]$.

В настоящее время идет активное изучение молекулярно-генетических аберраций низкодифференцированных глиальных опухолей (HGG) с изучением их прогностической и терапевтической ценностей. Так, в последнюю классификацию ВОЗ опухолей ЦНС для глиальных опухолей, помимо патоморфологических критериев (предложенных Daumas-Duport: атипия ядер, наличие митозов, пролиферация эндотелия сосудов, наличие некрозов), входят молекулярно-генетические аберрации (мутации генов IDH 1 и IDH 2; ко-делеция 1p/19q; метилирование промотора гена MGMT) [6, 7]

Гены IDH 1 и IDH 2 кодируют фермент изоцитратдегидрогеназу, который принимает участие в цикле Кребса. При высокодифференцированных глиальных опухолях (LGG) мутации в данных генах встречаются более чем в $90 \%[8,9]$. При ГБ мутации в данных генах встречаются примерно в 10 \% [6]. На основании этого сформулирована концепция «вторичной глиобластомы», которая произошла от глиомы grade II-III, относится к IDH-мутантному типу и обладает более благоприятным прогнозом [7].

В литературе есть данные о более длительном течении, а следовательно, более высокой выживаемости больных с IDH-мутантными опухолями [10, 11]. В то же время в работе, выполненной в Национальном научно-практическом центре нейрохирургии им. Н. Н. Бурденко, при ретроспективном анализе 84 пациентов с ГБ, проживших более 3 лет после первичной операции, не выявили достоверной разницы в выживаемости в зависимости от наличия мутации в гене IDH, определенной методом ИГX [12]. Наличие ко-делеции 1p/19q свидетельствует об олигодендроглиальном происхождении опухоли. Данный вид опухолей обладает хорошей чувствительностью к химиотерапии [13]. Наличие метилирования гена MGMT или снижение его экспрессии свидетельствуют о повышенной чувствительности к препаратам алкилирующего действия (темозоломид). Прогностическое значение мутаций в генах TERT, ATRX, P53 окончательно не определено и требует дальнейшего изучения $[8,14]$.

Следует признать, что в нашей стране на данный момент определение наличий мутаций в генах IDH 1 и IDH 2, метилирование гена MGMT доступно в основном в крупных федеральных центрах, в связи с чем существует необходимость поиска новых предикторов течения ГБ, а также определение их возможного сочетания с мутациями генов IDH 1 и IDH 2, статусом метилирования гена MGMT.
Молекулярно-биологические характеристики опухолевых клеток не только тесно связаны с их микроокружением, но и участвуют в его формировании. Микроглиальные клетки известны как антиген-презентирующие в ЦНС и, следовательно, обладают способностью к продукции различных цитокинов при активации антигеном, в качестве которого могут выступать и опухолевые клетки, несмотря на их аутологичное происхождение [15]. Кроме того, опухолевые клетки сами способны к гиперпродукции ряда цитокинов и факторов роста, формируя таким образом, пути своего распространения и создавая, как это ни выглядит парадоксально, защиту от иммунной системы.

Концепция «иммуноредактирования опухоли», получившая широкое признание в настоящее время, сводится к тому, что выжившие после первичного этапа лечения опухолевые клетки формируют локальную иммуносупрессию [16]. Снижение экспрессии молекул главного комплекса гистосовместимости, приводящее к нарушению распознавания опухолевых антигенов, а также повышение экспрессии молекул CTLA-4, PD-1, PDL-1, вызывающее анергию и апоптоз функционально активных иммунокомпетентных клеток, усиление неоангиогенеза и деградации экстрацеллюлярного матрикса, являются этапами данного процесса, в котором могут принимать участие и цитокины, что делает их объектом пристального внимания исследователей [17-19].

В данной статье приводится обзор литературы на основе анализа базы данных Pubmed о функциях, прогностической роли ряда цитокинов и их возможного использования в качестве мишеней для терапии ГБ.

Цитокины представляют собой гетерогенную группу полипептидов и гликопротеидов, обеспечивающих межклеточные взаимодействия, а также контакты между клеткой и внеклеточной средой. Основой иммунного ответа является межклеточная кооперация, которую обеспечивают цитокины, выполняя регуляторную функцию [20, 21]. Цитокины способны как стимулировать, так и подавлять иммунный ответ в зависимости от микроокружения.

Опухолевое микроокружение состоит из микроглии, которая составляет до 30 \% опухолевой массы при HGG, а также из эндотелиальных клеток, NK-клеток, антиген-представляющих клеток, лимфоцитов - как локальных, так и попадающих в мозг при нарушении гематоэнцефалического барьера. Клетки каждого из этих видов способны к продукции цитокинов, баланс которых может быть различным у разных больных, потенциально внося вклад в течение заболевания наряду с перечисленными выше молекулярно-генетическими особенностями опухолей [17, 20, 22].

Описана противоречивая роль микроглии в развитии, пролиферации и миграции опухолевых клеток [23], как и роль опухоль-инфильтрирующих макрофагов, обладающих оппозитными эффектами в зависимости от преимущественной принадлежности к М1 или M2 типу [24]. Секреция цитокинов в HGG отличается от здоровой мозговой ткани, что может служить диагностическим и прогностическим маркером, а в перспективе и мишенью для иммунотерапии $[18,25]$.

Цитокины разделяют на интерлейкины (IL) 1-36, ФР, КСФ, ФНО- $\alpha$ и $\beta$, интерфероны $(\alpha, \beta, \gamma$ и их подтипы) [19].

IL-1 синтезируется преимущественно активированными макрофагами и в меньшей степени В-лимфоцитами. Является ключевым медиатором иммунного ответа, обладает выраженной провоспалительной активностью, демонстрирует ряд централь- 
ных эффектов, описан как посредник нейроиммунных взаимодействий, стимулирует ангиогенез [26]. Повышенная экспрессия IL-1 $\beta$ отмечена как в клеточных линиях ГБ человека, так и в строме опухоли. В своей работе F. K. Hurmath с соавт. сообщили, что использование in vitro антагонистов IL-1 в клеточных линиях ГБ уменьшает пролиферацию, миграцию и инвазию клеток [27]. L. Tarassishin с соавт. отметили, что LGG, в отличие от HGG, не продуцируют IL-1, что может являться дополнительным дифференциальным маркером в определении степени злокачественности [28].

IL-2 обладает противоопухолевой активностью [29], способствует активации Т-хелперов, Т-киллеров, В-лимфоцитов, NK-клеток, макрофагов, повышает секрецию ФНО- $\alpha$, IL-1, IFN- $\gamma$, in vitro cпособствует образованию лимфокин-активированных киллеров (LAK), влияет на формирование и количество Т-клеток памяти [19, 30]. Несмотря на широкий спектр активности, работы по интратуморальному введению либо синтезу генетически модифицированными вирусами IL-2 в составе комбинированной иммунотерапии не увеличили медиану выживаемости пациентов [19, 31].

IL-4 секретируется T-лимфоцитами, NK-клетками, базофилами, эозинофилами, тучными клетками. IL-4 обладает противовоспалительной активностью, влияет на рост и дифференцировку В- и Т-лимфоцитов, тучных клеток; регулирует деятельность макрофагов; стимулирует рост Т-хелперов и Т-киллеров. IL-4 coвместно с IL-2 повышает пролиферацию предшественников, индуцирует дифференцировку Т-киллеров. B HGG отмечается повышенная экспрессия рецепторов к IL-4 [32], что предполагает его влияние на опухолевые клетки. Однако в единичных работах по интратуморальному введению конъюгатов IL-4 и экзотоксина Pseudomonas у пациентов с ГБ сообщается об отсутствии увеличения медианы выживаемости [33, 34].

IL-6 - плейотропный цитокин, способствующий активации и экспансии Т-лимфоцитов, дифференцировке В-лимфоцитов [35]. В ряде работ продемонстрировано изменение продукции и секреции IL-6 при многих злокачественных опухолях, в том числе ГБ [36, 37], а снижение его экспрессии замедляет рост опухоли на моделях ГБ человека, трансплантированной бестимусным мышам [38]. Показано, что IL-6 способствует росту и повышает резистентность опухолевых стволовых клеток к химиолучевой терапии [39]. У. Jiang с соавт. пришли к выводу, что блокирование рецепторов IL-6 в большей степени, в сравнении со снижением экспрессии самого цитокина, ингибирует рост ГБ in vitro $и$ in vivo, тем самым обосновав новый таргетный подход к лечению ГБ. Отмечено, что высокий уровень секреции IL-6, рецепторов IL-6 характерен для IDH-немутантного типа ГБ (IDH-wild type) и коррелирует с менее благоприятным прогнозом [7]. Также доказана сигнальная роль ядерного фактора активации Т-клеток в повышении экспрессии IL-6 и рецепторов IL-6 [40].

IL-8 продуцируется в основном активированными моноцитами и эпителиальными клетками. В ЦНC IL-8 влияет на синаптогенез, внутриклеточную концентрацию кальция и межсинаптическую передачу. Отмечено повышение концентрации IL-8 в ликворе в острую фазу воспалительных процессов, при черепно-мозговой травме [41]. Мутации гена, кодирующего IL-8, коррелируют с развитием злокачественных опухолей различной локализации, в том числе и головного мозга [42], а повышение экспрессии IL-8 в крови свидетельствует о прогрессии ГБ, увеличении перитуморального отёка и зон некроза [43]. При ГБ IL-8 стимулирует неоангиогенез, повышает инвазивность опухоли [41]. Повышение IL-8 в плазме и повышение экспрессии IL-8 в строме опухоли коррелировало с менее благоприятным прогнозом [44, 45]. Однако предложенные терапевтические подходы, направленные на снижение экспрессии IL-8, не изменили прогноз пациентов с ГБ [41].

IL-10 в основном продуцируется T-хелперами 2-го типа, моноцитами и считается универсальным ингибитором иммунного ответа. Повышение экспрессии IL-10 оказывает супрессорное действие на макрофаги, ингибирует синтез провоспалительных цитокинов Т-хелперами 1-го типа, нарушает взаимодействие антиген-представляющих клеток и Т-килеров [46]. В то же время встречаются единичные работы, в которых указывается на способность IL-10 повышать цитотоксичность Т-килеров [47]. При HGG в опухолевом микроокружении повышается экспрессия CD45+ и IL-10R по сравнению с метастазами, что может являться одним из дифференциальных критериев [48].

Антигенпрезентирующие клетки синтезируют IL-12, который активирует NK-клетки, стимулирует дифференцировку наивных Т-клеток (CD 4+, CD 8+) в Т-хелперы 1 типа и Т-килеры соответственно, влияет на созревание и длительность существования Т-клеток памяти, на взаимодействие врожденного и адаптивного иммунитета $[49,50]$. У. А. Barrett с соавт. оценивали эффект интратуморального введения генетически модифицированного аденовируса, способного синтезировать IL-12 при пероральном введении препарата «Веледимекс», проникающего через гематоэнцефалический барьер. Эксперимент проводился на бестимусных мышах с ортотопически привитой ГБ (GL-261). При завершении эксперимента на 85 день в основной группе 65 \% мышей оставались живыми. В контрольной группе мыши, получавшие бевацизумаб, имели медиану выживаемости 20 дней, темозоломид - 33 дня, блокаторы PD-1 - 37 дней. При аутопсии в контрольной группе отмечалась повышенная инфильтрация опухолевой массы лимфоцитами, уменьшение объема опухоли. Таким образом, авторами предложен новый иммунотерапевтический подход к лечению ГБ [51].

К противовоспалительным цитокинам относится IL-13, к которому имеются рецепторы, сходные по структуре и функции с IL-4R [19]. Отмечено повышение экспрессии IL-13R в глиальных опухолях по сравнению со здоровой тканью мозга. Описана корреляция как со степенью злокачественности глиом, так и с неблагоприятным исходом [52, 53]. Исследования, направленные на изучение цитотоксического влияния конъюгата IL-13 и экзотоксина Pseudomonas, зарегистрированного как Cintredekin besudotox, на ГБ показали свою эффективность in vitro и in vivo на моделях ГБ, привитых бестимусным мышам. Однако при клинических испытаниях I, II фазы выявлено значительное количество побочных эффектов, в виде нарастания отека головного мозга, без увеличения медианы выживаемости [53].

Эпителиальными и эндотелиальными клетками, а также развивающимися астроцитами синтезируется IL-33, необходимый в процессе развития для нормального числа синапсов и функционирования нервной цепи в спинном мозге и таламусе [54]. IL-33 влияет на активацию клеток иммунной системы: тучных клеток, моноцитов, эозинофилов, дендритных клеток, лимфоцитов. D. Gramatzki с соавт. не обнаруживали экспрессию IL-33 в участках здорового мозга; при этом она определялась у пациентов с первичными астроцитомами grade I-IV и с рецидивами ГБ, причем в последнем случае обнаружена достоверная взаимосвязь между уровнем экспрессии IL-33 и выживаемостью пациен- 
тов. Таким образом, определение мPHK IL-33 в крови может являться критерием эффективности лечения и прогрессирования у пациентов с HGG [55].

Важное значение отводится IFN- $\alpha$, с его иммуномодулирующим, антипролиферативным и антиангиогенным действием [19]. При клинических исследованиях 2 фазы у пациентов с рецидивом глиобластомы оценивалась эффективность химиотерапии темазоламидом в комбинации с подкожным введением IFN- $\alpha 2 \mathrm{~b}$ и пегилированной формой IFN- $\alpha 2 \mathrm{~b}$. При втором варианте терапии общая медиана выживаемости увеличилась на 3 месяца, но в то же время возросло число побочных эффектов (ТЭЛА, лейко- и тромбоцитопения) [56]. Изучение иммунотерапевтических подходов на модели глиобластомы человека, привитой гетеротопически бестимусным мышам, показало, что при добавлении к темозоламиду IFN- $\alpha$ повышался уровень экспрессии гена MGMT, что в свою очередь вело к снижению химиорезистентности [57], то есть, как и при других опухолях, IFN- $\alpha$ проявлял химиосенсибилизирующее действие.

Основной функцией IFN- $\gamma$ является цитотоксическое действие на клетки-мишени, в первую очередь на опухолевые клетки, экспрессирующие антигены главного комплекса гистосовместимости I типа с последующим распознаванием антигена CD8+ Т-лимфоцитами. IFN- $\gamma$ обладает антиангиогенным действием, усиливает экспрессию лигандов апоптоза (FAS-L, TRAl ligand) на поверхности иммунных клеток [19]. Было установлено статистически значимое снижение уровня IFN- $\gamma$ в крови пациентов с ГБ после комплексного лечения по сравнению с дооперационным периодом. Однако достоверно значимой корреляции между выживаемостью и уровнем IFN- $\gamma$ не обнаружено [58]. Использование IFN- $\gamma$ и циклофосфамида у 40 детей с HGG при проведении химиорадиотерапии не приводило к изменению медианы выживаемости [59].

\section{ヘитература/References}

1. Каприн А. Д., Старинский В. В., Петрова Г. В. Злокачественные новообразования в России в 2017 г. (заболеваемость и смертность). Москва, 2018. [Kaprin A. D., Starinskij V. V., Petrova G. V. Malignant neoplasms in Russia in 2017 (morbidity and mortality). Moscow, 2018. (In Russ.)].

2. Клинические рекомендации: Первичные опухоли центральной нервной системы. Министерство здравоохранения РФ, 2017. [Clinical recommendations: Primary tumors of the central nervous system. Ministry of the Russian Federation, 2017 (In Russ.)].

3. Greenberg M. S. Handbook of Neurosurgery. Eighth Edition, 2016:612-628.

4. Thakkar J. P., Dolecek T. A., Horbinski C., Ostrom Q. T., Lightner D. [et al.]. Epidemiologic and molecular prognostic review of glioblastoma. Cancer Epidemiol. Biomarkers Prev. 2014;23(10):1985-1996.

https://doi.org/10.1158/1055-9965.EPI-14-0275

5. Louis D. N., Perry A., Reifenberger G., von Deimling A., Figarella-Branger D. [et al.]. The 2016 World Health Organization Classification of Tumors of the Central Nervous System: a summary. Acta Neuropathol. 2016;131(6):803820. https://doi.org/10.1007/s00401-016-1545-1

6. Komori T. The 2016 WHO Classification of Tumours of the Central Nervous System: The Major Points of Revision. Neurol. Med. Chir. (Tokyo). 2017;57(7):301-311. https://doi.org/10.2176/nmc.ra.2017-0010

7. Wesseling P., Capper D. WHO 2016 Classification of gliomas. Neuropathol. Appl. Neurobiol. 2018;44(2):139-150. https://doi.org/10.1111/nan.12432

8. Cancer Genome Atlas Research. Comprehensive, Integrative Genomic Analysis of Diffuse Lower-Grade Gliomas. N. Eng. J. Med. 2015;372(26):2481-2498. https://doi.org/10.1056/nejmoa1402121

9. Aibaidula A., Chan A. K., Shi Z., Li Y., Zhang R. [et al.]. Adult IDH wild-type lower-grade gliomas should be further stratified. Neur. Oncol. 2017;19(10):1327-1337. https://doi.org/10.1093/neuonc/nox078
Заключение. Развитие медицинских технологий в XXI веке приводит к более глубокому изучению биологических процессов онкогенеза, что находит отражение в изменении классификаций опухолей, улучшении их диагностики, прогнозирования течения, и появлению новых подходов к лечению. Сущность трансляционной медицины, концепция которой является магистральной в течение последних лет, состоит в последовательном применении достижений фундаментальной науки для клинических целей. Однако в случае злокачественных опухолей головного мозга ее успехи оказались менее значимыми, чем в других областях онкологии.

В представленном обзоре дан анализ цитокинового микроокружения глиобластом, из которого видно, что применение массива данных может быть использовано если не для лечения (в связи с отсутствием какой-либо эффективности), то в качестве дополнительных прогностических критериев. Учитывая условное «разделение» ГБ на первичную и вторичную, то есть формирующуюся при прогрессивном озлокачествлении IDH-мутантных глиом grade II-III, возможна взаимосвязь этого процесса с характером цитокинового микроокружения, преобладанием в нем иммуносупрессивных цитокинов. Установленное значение неоангиогенеза в развитии глиом также предполагает негативную роль гиперпродукции провоспалительных цитокинов, традиционно не считающихся иммуносупрессивными, однако в данных условиях способствующих росту и трансформации опухоли. Следовательно, оценка локального содержания цитокинов при глиомах, как и при ряде других злокачественных опухолей, может оказаться прогностически значимой.

\section{Авторы заявляют об отсутствии конфликта} интересов.

10. Khan I., Waqas M., Shamim M. S. Prognostic significance of IDH 1 mutation in patient with glioblastoma multiforme. J. Pak. Med. Assoc. 2017;67(5):816-817.

11. de Quintana-Schmidt C., Alvarez-Holzapfel M. J., Nomdedeu-Guinot J., Bague-Rosell S., Gallego-Rubio O. [et al.]. Isocitrate dehydrogenase type I mutation as a prognostic factor in glioblastoma and a literature review. Neurocirugia. 2015;26(6):276-283.

https://doi.org/10.1016/j.neucir.2015.04.001

12. Горяйнов С. А., Гольдберг М. Ф., Голанов А. В., Золотова С. В., Шишкина Л. В. [и др.]. Феномен длительной выживаемости пациентов с глиобластомами. Часть I: роль клинико-демографических факторов и мутации IDH1 (R $132 \mathrm{H})$. Вопросы нейрохирургии им. Н. Н. Бурденко. 2017;81(3):5-16. [Goryaynov S. A., Gol'dberg M. F., Golanov A. V., Zolotova S. V., Shishkina L. V. [et al.]. The phenomen on of long-term survival in glioblastoma patients. Part I: the role of clinical and demographic factors and an IDH1 mutation (R $132 \mathrm{H})$. Voprosi neyrohirurgii im. N. N. Burdenko. - Burdenko's Journal of Neurosurgery. 2017;81(3):5-16. (In Russ.)].

https://doi.org/10.17116/neiro20178135-16

13. Weller M., Berger H., Hartmann C., Schramm J., Westphal M. [et al.]. Combined $1 \mathrm{p} / 19 \mathrm{q}$ loss in oligodendroglial tumors: predictive or prognostic biomarker? Clin. Cancer Res. 2007;13(23):6933-6937.

https://doi.org/10.1158/1078-0432.CCR-07-0573

14. Ohba S., Kuwahara K., Yamada S., Abe M., Hirose Y. Correlation between IDH, ATRX, and TERT promoter mutations in glioma. Brain Tumor Pathol. 2020;37(2):33-40. https://doi.org/10.1007/s10014-020-00360-4

15. Hanisch U. K. Microglia as a source and target of cytokines. Glia. 2002;40(2):140-155.

https://doi.org/10.1002/glia.10161

16. Gieryng A., Pszczolkowska D., Walentynowicz K. A., Rajan W. D., Kaminska B. Immune microenvironment of gliomas. Lab. Invest. 2017;97(5):498-518.

https://doi.org/10.1038/labinvest.2017.19

17. Choi B. D., Maus M. V., June C. H., Sampson J. H. Immunotherapy for Glioblastoma: Adoptive T-cell 
Strategies. Clin. Cancer. Res. 2019;25(7):2042-2048. https://doi.org/10.1158/1078-0432.CCR-18-1625

18. Chiorean R., Berindan-Neagoe I., Braicu C., Florian I. S. Leucuta D. [et al.]. Quantitative expression of serum biomarkers involved in angiogenesis and inflammation, in patients with glioblastoma multiforme: Correlations with clinical data. Cancer Biomark. 2014:14(2-3):185-194. https://doi.org/10.3233/CBM-130310

19. Chernov M. F., Muragaki Y., Kesari S., McCutcheon I. E. Intracranial Gliomas. Part III - Innovative treatment modalities. Basel: Karger, 2018:79-89.

20. Iwami K., Natsume A., Wakabayashi T. Cytokine networks in glioma. Neurosurg. Rev. 2011;34(3):253-263. https://doi.org/10.1007/s10143-011-0320-y

21. Iwami K., Natsume A., Wakabayashi T. Cytokine Therapy of Gliomas. Prog. Neurol. Surg. 2018;32:79-89. https://doi.org/10.1159/000469682

22. Charles N. A., Holland E. C., Gilbertson R., Glass R., Kettenmann $\mathrm{H}$. The brain tumor microenvironment. Glia. 2012;60(3):502-514. https://doi.org/10.1002/glia.21264

23. Hwang J. S., Jung E. H., Kwon M. Y., Han I. O. Glioma-secreted soluble factors stimulate microglial activation: The role of interleukin-1 $\beta$ and tumor necrosis factor- $\alpha$. J. Neuroimmunol. 2016;298:165-171.

https://doi.org/10.1016/j.jneuroim.2016.08.001

24. Szulzewsky F., Pelz A., Feng X., Synowitz M., Markovic D. [et al.]. Glioma-associated microglia/macrophages display an expression profile different from M1 and M2 polarization and highly express Gpnmb and Spp1. PLoS One. 2015;10(2): e0116644. https://doi.org/10.1371/journal.pone.0116644

25. Berlow N. E., Svalina M. N., Quist M. J., Settelmeyer T. P., Zherebitskiy V. [et al.]. IL-13 receptors as possible therapeutic targets in diffuse intrinsic pontine glioma. PLOS One. 2018;13(4):e0193565.

https://doi.org/10.1371/journal.pone.0193565

26. Kore R. A., Abraham E. C. Inflammatory cytokines, interleukin-1 beta and tumor necrosis factor-alpha, upregulated in glioblastoma multiforme, raise the levels of CRYAB in exosomes secreted by U373 glioma cells. Biochem. Biophys. Res. Commun. 2014;453(3):326-331. https://doi.org/10.1016/j.bbrc.2014.09.068

27. Hurmath F. K., Ramaswamy P., Nandakumar D. N. IL-1b microenvironment promotes proliferation, migration and invasion of human glioma cells. Cell. Biol. Int. 2014;38(12):1415-1422 https://doi.org/10.1002/cbin 10353

28. Tarassishin L., Casper D., Lee S. C. Aberrant Expression of Interleukin-1b and Inflammasome Activation in Human Malignant Gliomas. PLoS One. 2014;9(7):e103432. https://doi.org/10.1371/journal.pone.0103432

29. Hai B. O., Qia O., Jia L. I., Lian -Jie L. V., Ben-Jin Nie. [et al.]. The effects of interleukin 2 and rAd-p53 as a treatment for glioblastoma. Mol. Med. Rep. 2018;17(3):4853-4859. https://doi.org/10.3892/mmr.2018.8408

30. Kim E. S., Choi Y. E., Hwang S. J., Han Y. H., Park M. J. Bae I. H. IL-4, a direct target of miR-340/429, is involved in radiation-induced aggressive tumor behavior in human carcinoma cells. Oncotarget. 2016;7(52):86836-86856. https://doi.org/10.18632/oncotarget.13561

31. Barzon L., Pacenti M., Franchin E., Colombo F., Palù G. HSV-TK/IL-2 gene therapy for glioblastoma multiforme. Methods. Mol. Biol. 2009:542:529-549. https://doi.org/10.1007/978-1-59745-561-9 28

32. Bai F. L., Yu Y. H., Tian H., Ren G. P., Wang H. [et al.]. Genetically engineered Newcastle disease virus expressing interleukin-2 and TNF-related apoptosis-inducing ligand for cancer therapy. Cancer Biol. Ther. 2014;15:1226-1238. https://doi.org/10.4161/cbt.29686

33. Weber F., Asher A., Bucholz R., Berger M., Prados M. [et al.]. Local convection enhanced delivery of IL4-Pseudomonas exotoxin (NBI-3001) for treatment of patients with recurrent malignant glioma. Acta Neurochir Suppl. 2003;88:93-103. https://doi.org/10.1007/bf02700027

34. Rainov N. G., Heidecke V. Long term survival in a patient with recurrent malignant glioma treated with intratumoral infusion of an IL4-targeted toxin (NBI-3001). J. Neurooncol. 2004;66(1-2):197-201

https://doi.org/10.1023/b:neon.0000013478.27604.01

35. Hunter C. A., Jones S. A. IL-6 as a keystone cytokine in health and disease. Nat. Immunol. 2015;16(5):448-457. https://doi.org/10.1038/ni1117-1271b

36. Wang Y., Chen X., Tang G., Liu D., Peng G. [et al..]. AS-IL6 promotes glioma cell invasion by inducing H3K27Ac enrichment at the IL6 promoter and activating IL6 transcription. FEBS Lett. 2016:590(24):4586-4593. https://doi.org/10.1002/1873-3468.12485
37. Yao Y., Ye H., Qi Z., Mo L., Yue Q. [et al.]. B7-H4(B7x)-mediated cross-talk between Glioma initiating cells and macrophages via the IL6/JAK/STAT3 pathway lead to poor prognosis in Glioma patients. Clin. Cancer Res. 2016;22(11):2778-2790. https://doi.org/10.1158/1078-0432.CCR-15-0858

38. Weissenberger J., Loeffler S., Kappeler A., Kopf M., Lukes A. [et al.]. IL-6 is required for glioma development in a mouse model. Oncogene. 2004;23(19):3308-3316. https://doi.org/10.1038/sj.onc.1207455

39. Jin X., Kim S. H., Jeon H. M., Beck S., Sohn Y. W. [et al.]. Interferon regulatory factor 7 regulates glioma stem cells via interleukin-6 and notch signalling. Brain. 2012;135(Pt4):10551069. https://doi.org/10.1093/brain/aws028

40. Jiang Y., Han S., Cheng W., Wang Z., Wu A. NFAT1-regulated IL6 signalling contributes to aggressive phenotypes of glioma. Cell. Commun. Signal. 2017;15(1):54 . https://doi.org/10.1186/s12964-017-0210-1

41. Kosmopoulos M., Christofides A., Drekolias D., Zavras P Antonios N. [et al.]. Critical Role of IL-8 Targeting in Gliomas. Curr. Med. Chem. 2018;25:1954-1967. https://doi.org/10.2174/0929867325666171129125712

42. Liu H., Mao P., Xie C., Xie W. Wang M. Jiang H. Association between interleukin 8-251 T/A and $+781 \mathrm{C} / \mathrm{T}$ polymorphisms and glioma risk. Diagn. Pathol. 2015;10:138. https://doi.org/10.1186/s13000-015-0378-x

43. Henker C., Kriesen T., Furst K., Goody D., Glass A. [et al.]. Effect of 10 different polymorphisms on preoperative volumetric characteristics of glioblastoma multiforme. J. Neurooncol. 2016:126(3):585-592. https://doi.org/10.1007/s11060-015-2005-9

44. Zhang B., Shi L., Lu S., Sun X., Liu Y. [et al.]. Autocrine IL-8 promotes $\mathrm{F}$-actin polymerization and mediate mesenchymal transition via ELMO1-NF-kB-Snail signaling in glioma. Cancer Biol. Ther. 2015;16(6):898-911.

https://doi.org/10.1080/15384047.2015.1028702

45. Muller L., Muller-Haegele S., Mitsuhashi M., Gooding W., Okada H., Whiteside T. L. Exosomes isolated from plasma of glioma patients enrolled in a vaccination trial reflect antitumor immune activity and might predict survival. Oncolmmunology. 2015;4(6):e1008347

https://doi.org/10.1080/2162402X.2015.1008347

46. Geginat J., Larghi P., Paroni M., Nizzoli G., Penatti A. [et al.]. The light and the dark sides of Interleukin-10 in immune-mediated diseases and cancer. Cytokine Growth Factor Rev. 2016;30:87-93. https://doi.org/10.1016/j.cytogfr.2016.02.003

47. Oft M. Immune regulation and cytotoxic $T$ cell activation of IL-10 agonists - Preclinical and clinical experience. Semin. Immunol. 2019;44:101325. https://doi.org/10.1016/j.smim.2019.101325

48. Zadka L., Kram P., Koscinski J., Jankowski R., Kaczmarek M [et al.]. Association Between Interleukin-10 Receptors and the CD45-Immunophenotype of Central Nervous System Tumors: A Preliminary Study. Anticancer Res. 2017;37(10):5777-5783

https://doi.org/10.21873/anticanres.12019

49. Lippitz B. E. Cytokine patterns in patients with cancer: a systematic review. Lancet Oncol. 2013:14:e218-228. https://doi.org/10.1016/S1470-2045(12)70582-X

50. Klinke D. J. Enhancing the discovery and development of immunotherapies for cancer using quantitative and systems pharmacology: Interleukin-12 as a case study. J. Immunother. Cancer. 2015;3:27. https://doi.org/10.1186/s40425-015-0069-x

51. Barrett J. A., Cai H., Miao J., Khare P. D., Gonzalez P. [et al.]. Regulated intratumoral expression of IL-12 using a RheoSwitch Therapeutic System ${ }^{\circledR}(\mathrm{RTS} \otimes)$ gene switch as gene therapy for the treatment of glioma. Cancer Gene Therapy. 2018;25:106-116.

https://doi.org/10.1038/s41417-018-0019-0

52. Brown C. E., Warden C. D., Starr R., Deng X., Badie B. [et al.]. Glioma IL $13 R \alpha 2$ is associated with mesenchymal signature gene 592 expression and poor patient prognosis. PLoS One. 2013:8(10):e77769. https://doi.org/10.1371/journal.pone.0077769

53. Hung A. L., Garzon-Muvdi T., Lim M. Biomarkers and Immunotherapeutic Targets in Glioblastoma. World Neurosurg. 2017:102:494-506. https://doi.org/10.1016/j.wneu. 2017.03.011

54. Vainchtein I. D., Chin G., Cho F. S., Kelley K. W., Miller J. G. [et al.]. Astrocyte-derived interleukin-33 promotes microglial synapse engulfment and neural circuit development. Science. 2018;359(6381):1269-1273. https://doi.org/10.1126/science.aal3589 
55. Gramatzki D., Fre K., Cathomas G., Moch H., Weller M., Mertz K. D. Interleukin-33 in human gliomas: Expression and prognostic significance. Oncology Letters. 2016;12:445-452. https://doi.org/10.3892/ol.2016.4626

56. Groves M. D., Puduvalli V. K., Gilbert M. R., Levin V. A., Conrad C. A. [et al.]. Two phase II trials of temozolomide with interferon- $\alpha 2 \mathrm{~b}$ (pegylated and non-pegylated) in patients with recurrent glioblastoma multiforme. Br. J. Cancer. 2009;101(4):615-620. https://doi.org/10.1038/sj.bjc.6605189

57. Shen D., Guo C. C., Wang J., Qiu Z. K., Sai K. [et al.] Interferon- $\alpha / \beta$ enhances temozolomide activity against MGMT-positive glioma stem-like cells. Oncology Reports.
2015;34:2715-2721. https://doi.org/10.3892/or.2015.4232

58. Deniz C. D. Gürbilek M., Koc M. Prognostic value of interferon-gamma, interleukin-6, and tumor necrosis factor-alpha in the radiation response of patients diagnosed with locally advanced non-small-cell lung cancer and glioblastoma multiforme. Turk. J. Med. Sci. 2018;48(1):117-123. https://doi.org/10.3906/sag-1611-77

59. Wolff J. E., Wagner S., Reinert C., Gnekow A., Kortmann R. D. [et al.]. Maintenance treatment with interferongamma and low-dose cyclophosphamide for pediatric high-grade glioma. J. Neurooncol. 2006;79(3):315-321. https://doi.org/10.1007/s11060-006-9147-8

\title{
Сведения об авторах:
}

Кит Олег Иванович, доктор медицинских наук, профессор, член-корреспондент РАН, генеральный директор; тел.: 88632001000 (доб. 997); e-mail: onko-sekretar@mail.ru; https://orcid.org/0000-0003-3061-6108

Игнатов Сергей Николаевич, врач-нейрохирург, аспирант;

тел.: 89045040168; e-mail: Ignatov_Sergey_@mail.ru; https://orcid.org/0000-0001-8250-9617

Златник Елена Юрьевна, доктор медицинских наук, профессор,

главный научный сотрудник лаборатории иммунофенотипирования опухолей; тел.: 89612726968; e-mail: elena-zlatnik@mail.ru

Солдаткина Наталья Васильевна, доктор медицинских наук, старший научный сотрудник отделения общей онкологии;

тел.: 89185453004; e-mail: snv-rnioi@yandex.ru; https://orcid.org/0000-0002-0118-4935

Росторгуев Эдуард Евгеньевич, кандидат медицинских наук, заведующий отделением нейроонкологии;

тел.: 89289018024; e-mail: ed.rost@mail.ru; https://orcid.org/0000-0003-2937-0470

Сагакянц Александр Борисович, доцент, кандидат биологических наук, руководитель лаборатории иммунофенотипирования опухолей; тел.: 89604458653; e-mail: asagak@rambler.ru; https://orcid.org/0000-0003-0874-5261

Шульгина Оксана Геннадьевна, младший научный сотрудник;

тел.: 89185570986; e-mail: iftrnioi@yandex.ru; https://orcid.org/0000-0001-6828-145X

() Коллектив авторов, 2021

удК 616-005.8

DOI - https://doi.org/10.14300/mnnc.2021.16107

ISSN - 2073-8137

\section{ЭФФЕКТИВНОСТЬ И БЕЗОПАСНОСТЬ ПРИМЕНЕНИЯ МЕХАНИЧЕСКОЙ ТРОМБОЭКСТРАКЦИИ В КОМБИНАЦИИ С МЕАИКАМЕНТОЗНОЙ ТРОМБОАИТИЧЕСКОЙ ТЕРАПИЕЙ У ВЗРОСАЫХ ПАЦИЕНТОВ С ИШЕМИЧЕСКИМ ИНСУАЬТОМ: СИСТЕМАТИЧЕСКИЙ ОБЗОР}

\section{В. С. Аомбровский ${ }^{1}$, М. В. Авксентьев ${ }^{1,2}{ }^{2}$ В. В. Омельяновский ${ }^{1}$, Н. 3. Мусина ${ }^{1}$}

1 Центр экспертизы и контроля качества меАицинской помощи, Москва, Российская Фелерация

2 Первый Московский госуАарственный МеАицинский Университет им. И. М. Сеченова (Сеченовский Университет), Российская ФеАерация

\section{EFFICACY AND SAFETY OF MECHANICAL THROMBECTOMY IN COMBINATION WITH THROMBOLYTIC THERAPY IN PATIENTS WITH ISCHEMIC STROKE: A SYSTEMATIC REVIEW}

\author{
Dombrovskiy V. S. ${ }^{1}$, Avksentieva M. V. ${ }^{1}{ }^{2}$, Omelyanovsky V. V. ${ }^{1}$, Musina N. Z. ${ }^{1}$ \\ ${ }^{1}$ Center of Healthcare Quality Assessment and Control, Moscow, Russian Federation \\ 2 I. M. Sechenov First Moscow State Medical University (Sechenov University), \\ Russian Federation
}

С целью провести систематический обзор исследований, оценивающих клиническую эффективность и безопасность применения механической тромбоэкстракции (МТЭ) в сравнении с тромболитической терапией (ТЛТ), был проведен поиск научных публикаций в двух базах данных: Кокрановской библиотеке и базе данных Medline. B исследование включались только метаанализы (МА). Рассматривались все исходы, оценивающие эффективность и безопасность. В исследование было включено 20 публикаций. МТЭ в сочетании с ТЛТ статистически значимо улучшает функциональную способность пациентов, перенесших ишемический инсульт (ИИ), в сравнении с только ТЛТ. 